\title{
THE INFLUENCE OF CORONAVIRUS-19 OUTBREAK RISK PERCEPTION, PERCEIVED UNCERTAINTY ON JORDAN'S TOURISM BEHAVIORAL INTENTION
}

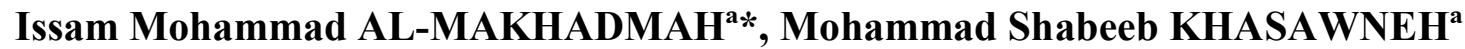 \\ ${ }^{a}$ Tourism Management Department, Ajloun College, Al-Balqa Applied University, Jordan, E-mail: \\ isammakhadmeh@bau.edu.jo, orcid.org/0000-0001-9672-5732; khasawnehmohammad79@bau.edu
}

Cite this article: Al-Makhadamah, I.M., Khasawneh, M. S., (2021). The Influence of Coronavirus-19 Outbreak Risk Perception, Perceived Uncertainty on Jordan's Tourism Behavioral Intention. Deturope, 13(1), 153-166.

\begin{abstract}
In this research, tourism was underlined as a health protection practice, which is focused upon the perception by individuals of Coronavirus-19 danger and uncertainty, particularly in Jordan perspective. The study investigates the effect on behavioral purpose on untact tourism of Coronavirus-19 risk perception and ambiguity, depended upon the theoretical models of the extended Theory of Planned Behavior (TPB) and the Health Belief Model (HBM). The online survey was conducted among Jordanian adults in April and May 2020. A total of 380 questionnaires about data collection were used. The results indicate that the perception of affective risk is a major precedent for attitude, while it has been shown that the perception of cognitive risk has a positive impact on attitude. There has also been a positive influence on perceptions on perceived ambiguity. This research has timely and insightful implications for tourism practitioners needed to prepare the post-corona sector for the new standard after the minimum living experience of an unexpected pandemic.
\end{abstract}

Keywords: Coronavirus-19, Perceived Uncertainty, Risk Perception, Jordan, Tourism

\section{INTRODUCTION}

Countries all over the world continue to suffer the harmful consequences of the Coronavirus19 pandemic (Davies, 2020). It started to spread to countries around the world after its first appearance in Wuhan, China on 31 December 2019 and the Announcement of the World Health Organization on 26 January 2020 on the high risk of outbreaks in Chino and around the world. People started flying from high-risk areas and were able to reach large airports freely without medical tests. For over a month after the rapid spread of Coronavirus-19, air traffic services operated with the minimal level of health surveillance at international borders (Strauss, 2020). Until 9 August 2020, there were still up to 19,462112 people in many countries testing positive and 722,285 deaths recorded. Preventive steps have been applied in several countries regarding the social dissociation and the introduction of total or partial containment. The following study was published by the Chinese National Health Commission 
which indicated that people carrying the virus could infect others through both respiratory and direct contact droplets on 27 January 2020. Furthermore, some Coronavirus-19 people without fever or radiological irregularities have made diagnosis difficult and social interactions very risky. This means that individual activity is important to control the spread of Coronavirus-19. This situation was caused by the closure of many schools in March 2020. The United Nations Scientific and Cultural Organization announced that 107 countries closed national schools, targeting 8,62 million children and young adults, or half of the world's population of students (Strauss, 2020; Lee \& Lee, 2020). This number then grew, and others had the same fate that contributed to the introduction of telecommunications. These adverse effects on the global economy subsequently prompted many countries to start thinking about efficient phased exit strategies and to return to their normal lives in order to revitalize trade and the economy. On its part, communities have had to regain their freedom, change the environment, relax and escape from their lifestyle in the home and understand the need for leisure at psychological level. It should also be noted that following the Coronavirus-19 exit containment plan, the holiday and travel needs of the public were not addressed at this time of the year and that in many countries around the world the tourism sector was fully standardized. Around 1,500000 tourists travel internationally every year, and it can be a strong way to spread a virus. As a result, travelers have had trouble travelling and taking advantage of travel rights and the services of hotel and tour operators. In the context of the forecasts of the World Tourism Organization (UNWTO) in the course of May 2020 it was estimated that foreign tourist arrivals would decrease by $78 \%$ and that the turnover would decline by US\$ 1.2 trillion and the direct jobs would be reduced by 120 million (Kim, 2020). Jordan citizens, in particular, started engaging in accidental travel activities to satisfy their travel and relaxation appetite while at the same time minimizing the possible risk of Coronavirus-19. People gave themselves to lonely healing during the pandemic by spending their time in nature, living in family housing, loving camping and road trips, or travelling on their own (Abu-Mater, Alsufy, \& Afifa, 2020). Regional walkways, forests and parks as their undisturbed tourist attractions have also been promoted by the local tourist authorities, and information on local scenic routes has also been made accessible for untact leisure. The hotels also offer intact services including private dining rooms, room buffet service and live chat concierge service. Health authorities have declared a code of conduct for 'intact tourism' that highlights the realistic guidelines for safe travel experiences aimed at social distance travelling such as utilizing private amenities at accommodations, keeping a space between restaurants and tables in cafes, encouraging outdoor activities rather than indoor activities, 
little visitors for a day and no touting at markets. Travel is a fundamental and basic require for modern people. Tourism as "one of the essential organized breaks in the normal life of every human being" as described by (Graburn, 1983). Nevertheless, risk variables like chronic illnesses may have a significant impact on decision-making in the field of travel (Chew \& Jahari, 2014). Individuals with a high level of health risk, according to the health-protective model (HBM), tend to increase their involvement in health-care activities to cope (Rosenstock, 1974). Individuals take part in auto protection activities as a mechanism to resolve their perceived threat when satisfying their travelling urge (Brewer, Weinstein, Cuite, \& Herrington, 2004). Intact tourism is underlined as an operation for health security emerging out of people's perception of the risk and uncertainty of Coronavirus-19. This research investigates the impact of Coronavirus-19 on behavioral intention towards untact tourism on the basis of the extended TPB and the HBM.

\section{LITERATURE REVIEW}

\section{Uncertainty and Risk}

Knight's recommended risk was a vital part of economic activity (1948). Since its foundation, hazards have known geological aspects such as tourism fields, sociological fields and marketing fields (Burton, Kates, \& White, 1978; Douglas \& Wildavsky, 1982; Bauer, 1960; Dholakia, 2001; Kahn \& Sarin, 1988; Marion, 2018), as he observed the concepts of risk and vulnerability,' Consumer behavior includes risks in the sense that any consumer action can lead to outcomes which are uncertain, and some are at least likely to be negative." In doing so, he introduced the two research streams contributed to the notion of threat and uncertainty perceived in purchasing behavior. The risk is the case where the decision-maker knows the consequences and their probability of events, and the situation in which the decision maker does not obtain such knowledge is unknown. There are two large streams of research on risk decision-making and insecurity: normative and descriptive. Models of standard study how risk and uncertainty decisions can be made, while descriptive experiments show how risk decisions and uncertainty are made. The initial stream considers uncertainty and risk as the same construct as suggested by (Shimp \& Bearden, 1982). Descriptive studies have shown the shortcomings of certain modeling rules in terms of the judgment and decision-making of individuals and have forced the creation of more nuanced models that better represent risky and unsure people's decision-making. Risk is perceived as a person's subjective feeling of insecurity that the potential purchases will be favorable (Cunningham, 1967). This approach, 
which defines uncertainty as a feature of risk, is still evident in contemporary study (Quintal, Lee, \& Soutar, 2010; Cho \& Lee, 2006; Crouch, Huybers, and Oppewal 2016). The second stream supports a distinction between risk and uncertainty. It's a "snario where something can happen and you have no idea what" (Hofstede, 2001, p.148). Definitions of perceived risk in marketing tend to be a distinction between risk and vulnerability even though perceived uncertainty has seldom been studied. The perceived risk is often designed as an anticipation of potential loss, which can be related to some measure of probability, in a subjectively described way (Quintal, et al., 2010; Dholakia, 2001; Sweeney, Soutar, \& Johnson, 1999). Therefore, the same result may be correlated with different levels of risk. "In fact, if the 'real world' exists and it is not perceptible by the individual, it cannot be influenced" (Bauer, 1960). In contrast, perceived insecurity is considered to be a subjectively determined expectation of potential loss uncertainty that cannot be measured for any possible outcome (Becker \& Knudsen, 2005). People would also encounter different degrees of uncertainty associated with the same outcome. Since the perceived risk was seen as a potential loss, some researchers suggested that perceived risk arises out of different types of potential losses as suggested by (Dholakia, 2001; Graburn, 1983). The hazards are known to be "a place where the number of possible events exceeds the real number of events and a certain amount of probability can be applied to them" (Stone \& Gronhaug, 1993). The performance risk is related to the fear of a purchase not working as needed or planned (Horton, 1976). The financial risk refers to the net financial loss possible in the transaction, including the possibility that the price of a commodity will be set, withdrawn or repaid (service) (Laroche, McDougall, Bergeron, \& Yang, 2004). The psychological risk is a result of anxiety or emotional distress from emotional reactions like worry and sorrow following purchases (Roehl \& Fesenmaier, 1992). Social risk refers to the "chance of a transaction that affects others' views" (Murray \& Schlacter, 1990). A potential health or appearance danger is a physical hazard. The risk of time is about the opportunity to buy or waste time too much (Murray \& Schlacter, 1990). Although the six types of potential losses have been studied for perceived risk, the perceived uncertainty can also be applied, as both mechanisms display trust in loss. Perceived uncertainty may therefore also be called multidimensional, economic, psychological, social, physical and time-related characteristics (Chew \& Jahari, 2014; Davies, 2020; Lee \& Lee, 2020; Dholakia, 2001). In that research, the HBM is utilized as a tool to describe the actions of citizens during the Coronavirus-19 pandemic. 


\section{Health Belief Model (HBM)}

HBM was first created by social psychologists at the American Public Health Service in 1950 (Rosenstock, 1974). The HBM was widely utilized as a conceptual structure to describe health behaviours. Health behaviour is defined as "any behaviour that may affect an individual's physical health or behaviour, which an individual believes may affect their physical health" (Sutton, 2004). One of the major factors that encourage human health promotion is that health risks are considered in the HBM (Bae \& Chang, 2020). It was built on cognition theory (Lewin, 1951). The HBM suggests that the understanding of personal health risk is informed by a minimum of three factors, general health principles, which include health interest and concern, basic health beliefs regarding the exposure to a specific health risk, and beliefs regarding the health effects (Lewin, 1951). If a person sees a threat to his or her wellbeing, is continuously encouraged to take action and the potential advantages overweight perceived obstacles, then preventive health measures are likely to be recommended. Compared to the stimulus response theory, which suggests that repeated behaviours result from an individual's immediate reward following a particular behaviour, cognitive theory stresses the importance of a subjective effect and the predictability of behavioural result (Bae \& Chang, 2020). When used on the health side, it is possible to infer that a person who values the avoidance of health risks always expects to reduce risk through a particular action that promotes health. HBM has been active in explaining various ways of using foetuses, including weight loss, vaccines, and diet (Hosseini et al., 2017; Bae \& Chang, 2020). Moreover, HBM was deemed useful in illustrating preventive health perceptions in the fields of tourism and hospitality. As it is much more infectious and vulnerable to SARS or MERS crises than in previous periods, the Coronavirus-19 pandemic affected the world, enabling people to take measures to promote their health. In this study, the purpose of this study would be to minimized human interaction and to address their Coronavirus-19 interpretation of risk as actions in protecting the health of individuals. This study is focused on the HBM system. In other words, HBM was referred to explain the correlation that has become important during the Coronavirus-19 Pandemic in Jordan. The hypothesis of perceived risks against Coronavirus-19 is that of tourism.

\section{Untact Tourism}

Untact is a "newly coined word first introduced in the book "Trend Korea 2018", referring to consumption behaviour that minimizes face-to-face contact" (Kim, 2017). In the digital era, the latest approach to customer service has unchanged (Lee \& Lee, 2020). They claimed that 
modern people who want to prevent unwelcome encounters with others prefer uncontaminated consumption, mainly because of technological innovation (Lee \& Lee, 2020). Since Coronavirus-19 spread in February 2020, using this word has become even more widespread, with applications like untact consumption, untact societies, untacte marketing, untact service, unstated recruitment and untact choice. In previous literature, Remote Service Meetings were mainly dealt with from a digitalised innovation point of view, particularly from an unequal perspective in the fields of marketing, service, finance, medicine, technology and hospitality (Bae \& Chang, 2020). Researchers (e.g. Kim \& Qu, 2014; Bae \& Chang, 2020; Lee \& Lee, 2020) discussed the main factors that influence consumer adoption of technology-based unattended services and their impacts on customer fulfilment and loyalty. Previous research into the concept of untact has mostly examined the individual features and technical experiences of modern people (Bae \& Chang, 2020). However, in the recent Coronavirus-19 pandemic, persons have practised untact lifestyle as a self-protected action to avoid hazards and seek protection, including the use of untact, technical facilities and non digitalised untact activities, such as remote nature camping or outdoor walks. The past of untact travel intention is checked using the extended TPB.

\section{PLANNED BEHAVIOR THEORY}

The study used the theory of anticipated action (TPB) as a main research model to describe the behavioral objective of choosing a destination. Ajzen \& Fishbein, (1980) first formulated the model, depended upon three concepts of attitudes, subjective norm, and perceived behavioral regulation. In addition, the model was considered an extension of the theory of rational action (TRA) in the prediction of human behavioral intention and the actual action taking into consideration issues associated with volitional and future control elements. A related model known as the TRA is descended by the TPB (Ajzen \& Fishbein, 1980). Conductivity typically leads to a positive or unpleasant attitude towards such behavior, moral beliefs lead to perceived social pressure or arbitrary expectations and control beliefs cause perceived behavioral control. The greater the conduct, the greater the subjective norm and the power perceived, the greater the purpose of the individual to conduct the behavior in question. The succession was attributed to the assumption that action is not entirely voluntary and cannot always be monitored; thus, the presumed behavioral regulation was introduced, and the theory was called the TPB with this addition. The TPB notes that any acts performed by a person are influenced by three types of aspects: behavioral beliefs (credence on the possible effects of the conduct practiced), normative beliefs (credence's on other people's normative 
expectations) and control beliefs (beliefs about the presence of factors that may enable or obstruct the performance of the behavior) (Ajzen \& Fishbein, 1980; Ajzen \& Driver, 1991; Bae \& Chang, 2020;). TPB has been exposed to a number of social behaviors with a high predictive utility (Conner, Warren, Close, \& Sparks, 1999; Ajzen \& Driver, 1991). Conner et al. (1999), however, reported that extra constructs could increase the predictive capacity of the TPB. The study then broadened the TPB model by introducing a risk perception and uncertainty to variable Coronavirus-19, taking into account the Coronavirus-19 crisis situations. This addition to the initial TPB model can be justified by using HBM, which show a person's propensity for health security actions in the face of potential threats and uncertainty. In other words, the dysfunctional tourism activity in conjunction with their perception of the Coronavirus-19 crisis is viewed as an attempt to protect and/or improve people's health. Past conduct has had significant effects on the development of behavioral intention and the actual conduct (Lam \& Hsu, 2006; Bae \& Chang, 2020; Quellette \& Wood, 1998). This study therefore suggested that past conduct be included in the research context to predict travel destination choices. In our research context, however, we did not include unique HBM variables; rather, we used TPB variables to keep this analysis in focus.

\section{Past Behavior}

Human behavior theory notes that a frequency of past behavior is the best indicator of the purpose of behavior and possible actual behavior (Lam \& Hsu, 2006; Sonmez \& Graefe, 1998). One of the possible explanations is that people want to preserve the continuity of actions and value (Conner et al., 1999; Lee \& Lee, 2020). Although the TPB has been regarded as a reliable behavioral intention forecasting model, Sonmez and Graefe (1998) noticed that when past activity was integrated into the TPB model, there was a greater variation in behavioral intention explanation. Bae \& Chang, (2020) and Laroche et al., (2004) also considered previous behavior, although their connection was poor, as a major foretaste of travelers' intent to choose a destination. It can therefore be fairly assumed to improve the predictive potential for the original TPB by including past activities into the study model. In the Coronavirus-19 pandemic in Jordan the pattern of unspoilt tourism was observed. The research has started with the goal of examining the correlation between this pattern and the outbreak of Coronavirus-19, since Jordanians seem to be finding their strategies to cope to reduce perceived risks, and in the meantime, meet their travel needs. HBM offers an ideal context in this respect for uncontaminated travel as health-resistant behavior, in response to 
the perception of the risk of Coronavirus-19 among individuals. By creating a research model with another risk perception component, we use an extended TPB to anticipate the rising untact tourist in the Coronavirus-19 pandemic (Figure 1).

Figure 1 The research model

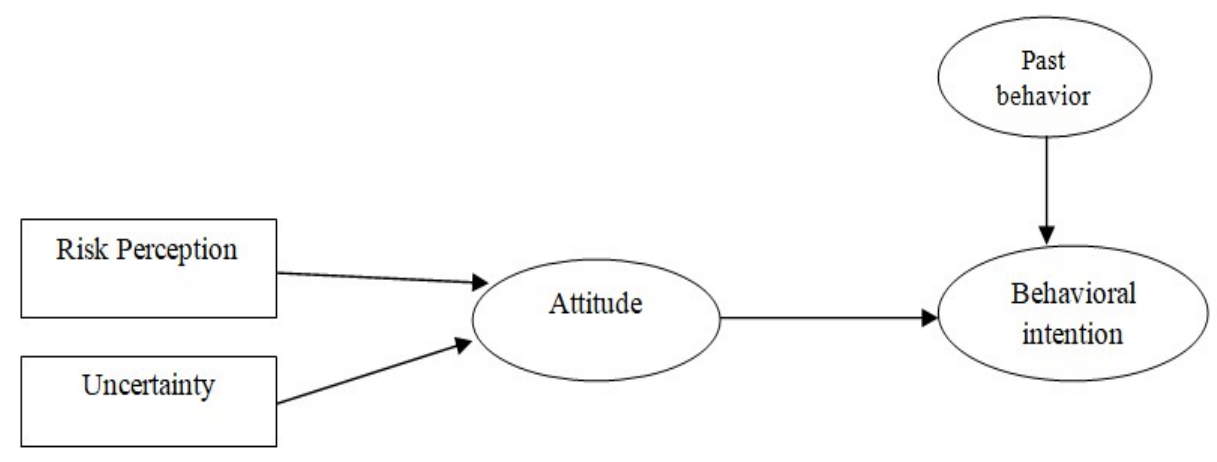

\section{METHODS}

Jordanian adults were part of the population in this sample. It is understood that this target market consists of important decision-makers for travel. At the height of the pandemic, from May 5 to June 30, 2020, an online questionnaire was circulated. This collection of data is significant during the pandemic as it provides a basis for the observation of long-term behavioral changes from a longitudinal point of view in a series of following study (Novelli, Burgess, Jones, \& Ritchie, 2018). For example, Novelli et al. (2018) studied the spillover effects of the Ebola tourism crisis in three phases: begin of the high season, high season high and post-crisis period. A quota sampling procedure was used to select respondents based on sex, age and marital status. The study carried out the first pilot survey with 30 people to determine the initial reliability of our measurements and ensure the precision of the questionnaire. The primary survey then used a total of 1,200 anonymous online survey. In all, 593 survey respondents accessed the survey link, 419 finished the survey, and 380 valid responses were used to perform the final data analysis after removal of incomplete or insincere questionnaires. Table (1) shows the population information of the participants. The age of 61.84 was the norm, with considerably more women than men (28.68 percent) participants (71.31 percent). Around half of the attendees were married. This age group was chosen because it represents the youth and the beginning of old age to cover the impact of the Corona virus on two age groups. 
Table 1 Demographic Information

\begin{tabular}{|c|c|c|c|}
\hline & & $\mathrm{n}$ & $\%$ \\
\hline \multirow{3}{*}{$\begin{array}{l}\text { Gender } \\
\text { Age }\end{array}$} & Male & 271 & 71.31 \\
\hline & Female & 109 & 28.68 \\
\hline & $\begin{array}{l}25-35 \\
36-50\end{array}$ & $\begin{array}{l}145 \\
235\end{array}$ & $\begin{array}{l}40.52 \\
61.84\end{array}$ \\
\hline $\begin{array}{l}\text { Marital } \\
\text { status }\end{array}$ & $\begin{array}{l}\text { Single } \\
\text { Married }\end{array}$ & $\begin{array}{l}133 \\
247\end{array}$ & $\begin{array}{l}35 \\
65\end{array}$ \\
\hline
\end{tabular}

\section{Measurement Model}

RMSEA $=0.081, \mathrm{NFI}=0.775$ and CFI $=0.800$ were suggested for the measurement model According to Kline, (1) the root-aware mean square error (RMSEA) must be less than 0.08 , and (2) the fitness of the model with the fitness of a null hypo thesis should be shown by the comparative index (CFI) as well as by the standard fit index (NFI). Indicating internal accuracy of construction metrics, the composite reliability (CR) value was above 0.7 . The average variance derived (AVE) was greater than 0.5 and verified the latent variables' explanatory ability. Table (2) also shows the alpha values of Cronbach for the evaluation of the reliability of the multi-item scales, ranging from $0.881-.951$. Both alpha coefficients for each construction were above the cutoff point of 0.7 , indicating appropriate protection.

Table 2 Cronbach Value

\begin{tabular}{lccc}
\hline \multicolumn{1}{c}{ Variables } & Factor loading & C.R. & AVE \\
\hline Cognitive Risk Perception $(\alpha=.881)$ & & .881 & .634 \\
CRP1 & .654 & & \\
CRP2 & .765 & & \\
CRP3 & .671 & & .678 \\
CRP4 & .785 & & \\
Uncertainty Perception $(\alpha=.901)$ & & & \\
UP1 & .725 & & \\
UP2 & .712 & .677 \\
UP3 & .701 & \\
UP4 & .794 & \\
Attitude $(\alpha=.951)$ & & & \\
A1 & .658 & \\
A2 & .835 & .861 \\
A3 & .865 & \\
A4 & .854 & \\
Past Behavior $(\alpha=.932)$ & & & \\
PB1 & .817 & \\
PB2 & .821 & \\
PB3 & .830 & \\
Behavioral Intention $(\alpha=.941)$ & & & \\
BI1 & .724 & \\
BI2 & .768 & \\
BI3 & .711 & \\
BI4 & .765 & \\
\hline
\end{tabular}




\section{RESULTS}

\section{Structural Model}

Next, to perform further verification, SEM was used (Figure 2). For the structural model, the goodness-of-fit indices were $\mathrm{RMSEA}=0.080, \mathrm{CFI}=0.888$, and NFI $=0.881$, indicating a good fit for the results. The interpretation of cognitive risk showed a substantially positive effect on attitude $(\beta=0.184, p<0.000)$. The experience of uncertainty showed a substantially positive effect on attitude $(\beta=0.194, \mathrm{p}<0.000)$. Positive influences on behavioral intention were attitude, perception of cognitive risk, perception of ambiguity and previous experience $(\beta=0.195, \mathrm{p}<0.000 ; \beta=0.218, \mathrm{p}<0.000 ; \beta=0.175, \mathrm{p}<0.000 ; \beta=0.281, \mathrm{p}<0.000)$.

Figure 3 Structural equation model

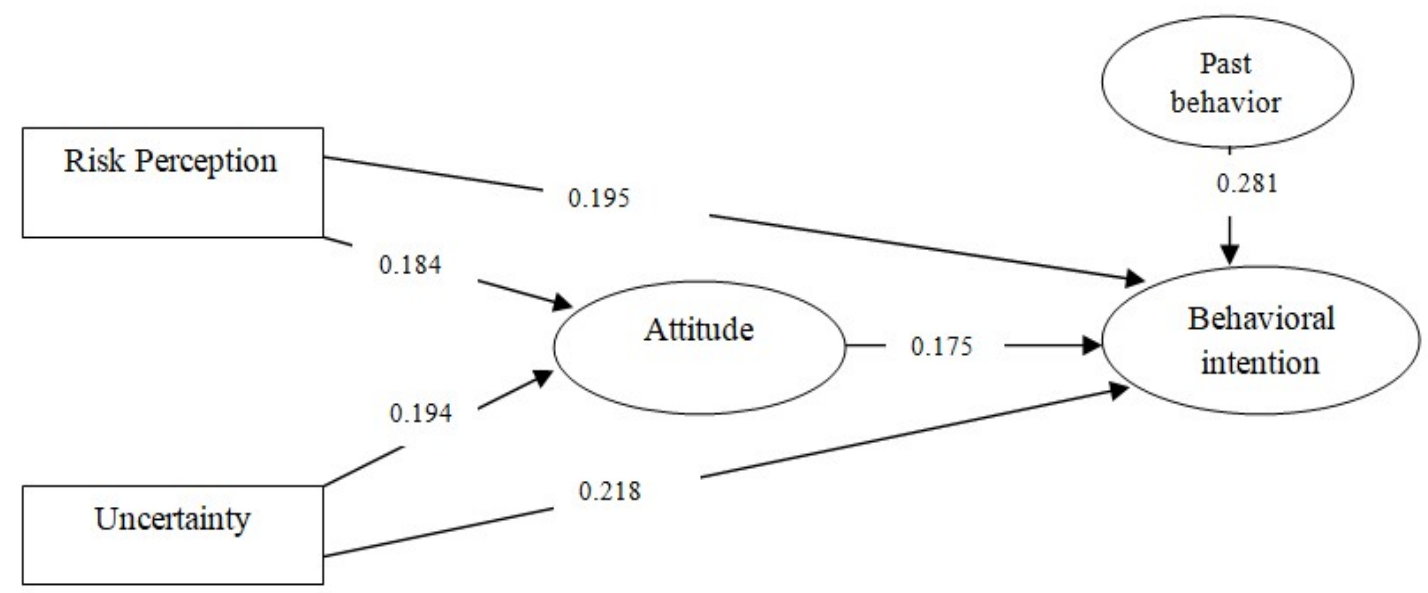

\section{DISCUSSION}

The goal of this research was to study the effect of Coronavirus-19 on the behavioral aims of unchanged tourism via an extended TPB Pandemic. In particular, it reveals valuable insights into untact tourism as risk reduction or health measures resulting from Coronavirus-19 analysis of the HBM-based risks. The key outcomes of this study are below. First, the findings demonstrate a positive correlation between the uncontaminated tourism position, in line with the findings from (Bae \& Chang, 2020), (Hosseini et al., 2017) and (Kim, 2020). The impact of attitude on the compartmental target, however, correlates significantly to Ajzen's suggestion (1980) and previous studies of attitude focused on behavioral objectives (e.g. Quintal et al., 2010; Kim \& Qu, 2014). Behavioral purpose is profoundly influenced by previous activity. This result is in line with Ajzen's (1980) claim that previous experience can aid in shaping conscious intentions intentionally. The findings also show that empirical studies partly validated show that past comportment influences the comfort and actual actions 
of different modes of action (e.g., Ajzen \& Driver, 1991; Ajzen \& Fishbein, 1980). Cognitive risk awareness had a substantial positive influence on behavior. Uncertainty has a major positive impact on behavior. Place, cognitive perceptions of risk, perception of vulnerability and past acts that were in line with (Quintal et al., 2010; Lee \& Lee, 2020) were positively affected by behavior intentions (Bae \& Chang, 2020).

\section{IMPLICATIONS AND CONCLUSION}

This paper provides a timely and detailed discussion of the impact of Coronavirus-19 on behavioral changes in this unrivalled visitor pandemic. Added, it has investigated a vast part of Jordan side of behavioral changes in this pandemic for certain areas. It is focused on a fast collection of and understanding data at the height of the pandemic and has several theoretical implications. First of all, the study shows the academic effort to interpret the ongoing global crisis, which has triggered serious upheavals in tourist literature in the world and in the lives of people. The results of this study will provide an important reference point for follow-up in the autumn after the temporary world relief, given the likely second wave of Coronavirus-19. The findings of this study will provide a valuable point of reference in the autumn following a temporary reduction of the global spread of the potential second wave of Coronavirus- 19 for longitudinal studies to track long-term and short-term behavioral improvements for the tourists recommended by (Gössling, Scott \& Hall, 2020). Secondly, this research used the idea of untact to describe tourist actions during the pandemic to visitors. The term was particularly highlighted as an HBM component and was mainly explored technically in previous studies. This study looked at 'untact' as a key concept to show a 'new norm' tourism conduct which fulfils people's urge to travel during a pandemic even when the risk of the disease is minimized. Individuals that are used to protect their wellbeing will unchanged behavior to contribute to potential post-corona studies.

For instance, breakfast buffets at luxurious hotels utilized to be one of the most enticing aspects of attracting visitors in Jordan, while room service received considerably less attention. Nevertheless, due to visitors want to ensure safety, room service of the breakfast buffet has gained much popularity since the outbreak of COVID-19. Visitors would like to attend tourism programmes in a small group on a reservation basis. Hotels may need to provide a highly personalized room based on visitors' needs to protect their personal spaces. Strictly certified services, spaces, or programmes in terms of their safety would meet the increased demand for untact tourism. Tourism practitioners would be able to drive the 
message regarding their efforts in practicing untact as a safeguard for tourists' safe travel experiences. Thirdly, the study expanded the theory of predicted behavior with the interpretation of vector risk. The results from this study provide nuanced information on visitor actions during potential outbreaks of infectious diseases.

Considering their contributions, this analysis is not limitless. Secondly, this study includes cross-sectional results. The intention to carry out after the end of Corona during the pandemic does not continue. Researchers can collect more information in a variety of periods for a longitudinal study of the issue. In this case, it is also important to analyze the connection between behavioral intent in the earlier period and actual measures in the latter. In the secondplace Jordanian societies were based on the results of the study as well as might the results not apply to other countries due to differences in perspective and a research model should be validated in various contexts. Moreover, exploring the motivating factors of untact tourism is significant. In the Coronavirus-19 pandemic from the different perspectives of tourists, industry, and academia, it will also be important to expand the understanding of this alternative from of tourist.

\section{REFERENCES}

Abu-Mater, W., Alsufy, F., \& Afifa, M (2020). The Effect of Coronavirus (Covid-19) on the Jordanian Economy: A Comprehensive Analysis of the Economy and How to Return Growth Rapidly. Journal of Accounting, Finance \& Management Strategy, 15(2), 1-30.

Ajzen, \& Driver. (1991). Prediction of leisure participation from behavioral, normative, and control beliefs: An application of the theory of planned behavior. Leisure Science, 13(4), 185-204.

Ajzen, I., \& Fishbein, M. (1980). Understanding attitudes and predicting social behavior. Englewood Cliffs, New Jersey: Prentice Hall.

Bae, S., \& Chang, P. (2020). The effect of coronavirus disease-19 (COVID-19) risk perception on behavioural intention towards 'untact' tourism in South Korea during the first wave of the pandemic (March 2020). CURRENT ISSUES IN TOURISM https://doi.org/10.1080/13683500.2020.1798895.

Bauer, R. (1960). Consumer behavior as risk-taking. In R. S. Hancock (Ed.), Dynamic marketing for a changing world (pp. 389-398). Chicago, IL: American Marketing Association.

Becker, M., \& Knudsen, T. (2005). The role of routines in reducing pervasive uncertainty. Journal of Business Research, 58(6), 746-757.

Brewer, N . Weinstein, N., Cuite, C.,\& Herrington, J.(2004). Risk perceptions and their relation to risk behavior. Annals of Behavioral Medicine, 27(2), 125-130. https://doi.org/10.1207/s15324796abm2702_7.

Burton, I. Kates ,R., \& White, G. (1978). The environment at hazard. Oxford, UK: Oxford University Press. 
Chew, E. Y., \& Jahari, S. A. (2014). Destination image as a mediator between perceived risks and revisit intention: A case of post-disaster Japan. Tourism Management, 40, 382-393. https://doi.org/10.1016/j.tourman.2013.07.008.

Cho, J., \& Lee, J. (2006). An integrated model of risk and risk-reducing strategies.Journal of Business Research, 59(1), 112-120.

Conner, M., Warren, R., Close, S., \& Sparks, P. (1999). Alcohol consumption and the theory of planned behavior: An examination of the cognitive mediation of past behavior. Journal of Applied Social Psychology,29(8), 1676-1704.

Crouch, G. I., Huybers, T., Oppewal, H. (2016) Inferring future vacation experience preference from past vacation choice: A latent class analysis. Journal of Travel Research, 55 (5): 574-87.

Cunningham, S. (1967). The major dimensions of perceived risk. In D. Cox (Ed.), Risk taking and information handling in consumer behavior (pp. 82-108). Boston, MA:Harvard University Press.

Davies, W. (2020). The last global crisis didn't change the world. But this one could. The Guardian. March 24, 2020. https://www.theguardian.com/commentisfree/2020/mar/24/ coronavirus-crisis-change-world-financial-global-capitalism

Dholakia, U. (2001). A motivational process model of product involvement and consumer risk perception. European Journal of Marketing, 35(11/12),1340-1360.

Douglas, M., \& Wildavsky, A. (1982). Risk and culture. Berkeley, CA: University of California Press.

Gössling, S. Scott, D., \& Hall, M. (2020). Pandemics, tourism and global change: A rapid assessment of COVID-19. Journal of Sustainable Tourism, 29(1), 1-20. https://doi.org/ 10.1080/ 09669582.2020.1758708.

Graburn, N. H. (1983). The anthropology of tourism. Annals of Tourism Research, 10(1), 933. https://doi.org/10.1016/0160-.

Hofstede, G. (2001, p.148). Culture's consequences: Comparing values, behaviors, institutions and organizations across nations. Beverly Hills, CA: Sage Publications.

Hosseini,Z., Karimi,Z., Mohebi,S. Sharifirad, G. Rahbar, A., \& Gharlipour, Z. (2017). Nutritional preventive behavior of osteoporosis in female students: Applying health belief model (HBM). International Journal of Pediatrics, 5(1), 4137-4144. doi: 10.22038/ijp.2016.7560

Kahn, B., \& Sarin, R. (1988). Modeling ambiguity in decisions under uncertainty. Journal of Consumer Research, 15(2), 265-271.

Kim, H. (2020). The endless battle against COVID-19. Everything has changed in South Korea. Segye Daily. May 15, 2020.

Kim, M., \& Qu, H. (2014). Travelers' behavioral intention toward hotel self-service kiosks usage. International Journal of Contemporary Hospitality Management, 26(2), 225245. https://doi.org/10.1108/IJCHM-09-2012-0165.

Kim, N. (2017). Trend Korea 2018. Miraebook Publishing.

Knight's, F. (1948). Risk, uncertainty and profit. Boston, MA: Houghton-Mifflin.

Lam, T. Hsu, C. H. C. (2006). Predicting behavioral intention of choosing a travel destination. Tourism Management 27 (5) 589-599.

Laroche, Z., McDougall, G. H., Bergeron, J., \& Yang, Z. (2004). Exploring how intangibility affects perceived risk. Journal of Service Research, 6(4), 373-389.

Lee, J., \& Lee, C. (2020). Over the half of the adults in Korea have experienced Corona Blue. April 14, 2020. https://biz.chosun.com/site/.

Lewin, K. (1951). Field theory in social science. Harper Row. 
Marion, Karl. (2018) Risk and Uncertainty in Travel Decision-Making: Tourist and Destination Perspective. Journal of Travel Research, 57(1), 129-146. doi: 10.1177/0047287516678337.

Murray, K., \& Schlacter, J. (1990). The impact of services versus goods on consumers' assessment of perceived risk and variability. Journal of the Academy of Marketing Science, 18(1), 51-65.

Novelli, M., Burgess, L. G., Jones, A., \& Ritchie, B. W. (2018). 'No Ebola...still doomed'The Ebola-induced tourism crisis. Annals of Tourism Research, 70, 76-87. https://doi.org/10.1016/j.annals.2018.03.006.

Quintal, V. A., Lee, J. A., \& Soutar, G. N. (2010). Risk, uncertainty and the theory of planned behavior: A tourism exampleq. Tourism Management 31 (2010) 797-805.

Roehl, W., \& Fesenmaier, D. (1992). Risk perceptions and pleasure travel: an exploratory analysis. Journal of Travel Research, 30(4), 17-26.

Rosenstock, I. M. (1974). Historical origins of the health belief model. Health Education Monographs, 2(4), 328-335.

Shimp, T., \& Bearden, W. (1982). Warranty and other extrinsic cue effects on consumers' risk perceptions. Journal of Consumer Research, 9(1), 38-46.

Sonmez, S., \& Graefe, A. (1998). Determining future travel behavior from past travel experience and perceptions of risk and safety. Journal of Travel Research, 37(4), 171177.

Stone, R., \& Gronhaug, K. (1993). Perceived risk: further considerations for the marketing discipline. European Journal of Marketing, 27(3), 372-394.

Strauss, V. (2020). 1.5 billion children around globe affected by school closure. What countries are doing to keep kids. The Washington Post 27. 3. 2020. https://www.washingtonpost. com/ education/2020/03/26/nearly-14-billion-childrenaround-globe-are-out-school-heres-what $\quad$-countries-are-doing-keep-kids-learningduring-pandemic/

Sutton, S. (2004). Determinants of health-related behaviours: Theoretical and methodological issues. The Sage Handbook of Health Psychology, 94-126. https://doi.org/ 10.4135/9781848608153.n4.

Sweeney, J., Soutar, G., \& Johnson, L. (1999). The role of perceived risk in the quality-value relationship: a study in a retail environment. Journal of Retailing, 75(1), 77-105. 